van BuiJtenen, H. P. (1983): Progeny test design and analysis. Proc. South. Tree Improv. Conf. 17: 161-170.

WRIGHT, J. W. (1976): Introduction to forest genetics. Academic Press Inc., New York, N.Y.
XIANG, B. and B. LI (2003): Best linear unbiased prediction of clonal breeding values and genetic values from full-sib mating designs. Can. J. For. Res. 33: 2036-2043.

\title{
Genetic Parameters and Strategies for Genetic Improvement of Stiffness in Radiata Pine
}

\author{
By S. KumaR ${ }^{1), *)}$, H. S. DungeY ${ }^{1)}$ and A. C. Matheson ${ }^{2)}$
}

(Received $13^{\text {th }}$ October 2005)

\begin{abstract}
The two main objectives of this study were: (1) to determine how early is it possible to undertake selection to improve the stiffness of corewood; (2) to determine if the selection based on corewood stiffness could also improve outerwood stiffness, and vice versa. Breastheight data from two progeny trials of Pinus radiata D. Don were used. In the first trial (age 30 years), data on Silviscan predicted stiffness $(\mathrm{MoE})$ was obtained for each growth ring on each core sample from 50 open-pollinated families. In the second trial (age 14 years), data on static-bending MoE was obtained using clearwood sticks $(300 \times 20 \times 20 \mathrm{~mm})$ cut from each tree from 18 control-pollinated families. MoE varied from $3.5 \mathrm{GPa}$ in rings $1-5$ to about $17 \mathrm{GPa}$ in rings $21-25$. Coefficients of variation of corewood and outerwood MoE were about $20-30 \%$ and $15-20 \%$ respectively. Estimates of narrowsense heritability for $\mathrm{MoE}$ were generally higher $(0.50-0.70)$ in the corewood compared with the outerwood (0.15-0.30). Early selection for MoE could yield substantial gain in corewood MoE but only small gains, if any, in outerwood MoE (especially for rings 21-30). Estimated genetic correlations between density and stiffness appeared moderate in the corewood zone, but high in the outerwood zone. Selection based on density (using 5-mm cores) and acoustic stiffness (using standing tree tools), assessed at age 6-7 years, appeared to be a good option to improve both corewood and outerwood stiffness.
\end{abstract}

Key words: Stiffness, sound velocity, wood density, heritability, breeding strategy, genetic correlation, age-age correlation, early selection, Pinus radiata.

\section{Introduction}

Interest in the genetic improvement of wood properties of radiata pine (Pinus radiata D. Don) has increased to an all-time high. This is mainly driven by the aim to increase the recovery of higher-grade of sawn timber. Wood stiffness, measured as modulus of elasticity (MoE), is a key property of structural sawn timber. Low

\footnotetext{
1) Ensis-Genetics, Private Bag 3020, Rotorua, New Zealand.

2) Ensis-Genetics, PO Box E4008, Kingston ACT 2604, Australia.

*) Corresponding author: Tel.: +64 7343 5899, Fax: +64 73480952 , Email: Satish.Kumar@forestresearch.co.nz
}

stiffness is an important limitation of radiata pine timber, especially when grown on the short rotations (25-30 years), which affects the quality and performance under certain specific usage. Such rotations result in a high proportion of corewood (the first 10 rings or so from the pith) leading to an associated reduction in wood quality (Cown et al., 1987; Cown et al., 1999) because corewood has poorer wood quality for most applications. Various direct, indirect and surrogate tests can be used to estimate wood stiffness (BETHGE and MATtheCK, 1998; XIPING et al., 2000; JAYAWICKRAMA, 2001; KumAR et al., 2002; LinTSTRÖM et al., 2002; MATHESON et al., 2002):

(1) Stiffness can be measured directly on sawn lumber; however, this would be very expensive for ranking genotypes, and trees cut down for testing would no longer be available for breeding or other work unless clonally replicated.

(2) Small clear wood specimens (taken from the tree at breast-height or from inside the felled stem) are another option, and specimens of $300 \times 20 \times 20 \mathrm{~mm}$ have been used routinely in New Zealand (e.g. BIER and BRITTON, 1999).

(3) SilviScan, a wood microstructure analyser (Evans, 2003), can be used to obtain predicted MoE for different rings by scanning strips cut from 12 -mm increment cores.

(4) Stiffness can be measured indirectly through acoustic tools, such as HITMAN, which measures resonance in logs (HARRIS and ANDREWS, 1999), or IML Hammer, which measures the elapsed time of propagation of an acoustic stress wave in standing trees (ANONYMUs, 2001).

Timber stiffness of radiata pine was identified as a priority for the New Zealand radiata pine breeding programme in 1997 (SoRENSSON, unpublished), with highranking parents (for growth and form traits) being subsequently ranked for stiffness and various other wood properties. As a result, a large number of parents of the New Zealand radiata pine breeding population have been ranked for breeding values, based on acoustic stiffness (KUMAR, 2004). HITMAN measurements require felled logs, which means that selected trees will not be available for propagation as forward selections or re- 
testing for stiffness at any later age is impossible. Several studies have shown that measurement of sound velocity can be used as a very good predictor of wood stiffness in standing trees (Ross and PELLERIN, 1991; Ross, 1999; WALKER and NAKADA, 1999; LAUNAY et al., 2002; Matheson et al., 2002; Kumar, 2004). Following these successful preliminary studies, various non-destructive standing-tree tools are currently being used for ranking families for stiffness.

Some of the open-pollinated (OP) radiata pine families that are now being considered for assessment of stiffness are about 15-20 years old. Earlier there were some suggestions that stiffness assessed using standing-tree tools on older trees may represent stiffness of a few outer rings only. However, a recent unpublished study, using a refined version of the IML Hammer, estimated the correlation between the IML Hammer and average lumber stiffness as 0.70 and 0.75 in 16- and 25-year-old radiata pine trees respectively. XIPING et al. (2000) also reported a strong relationship between stress wave propagation in standing trees and average static-bending MoE of small clear wood specimens obtained from 38 to 70-years-old trees of western hemlock and Sitka spruce. None of the standing-tree tools, however, reveal the pith-to-bark values of $\mathrm{MoE}$, which is essential to help predict outerwood stiffness from corewood stiffness, and vice versa. Since the corewood occupies a considerable proportion of short-rotation radiata pine logs, the low stiffness of the corewood is deleterious for several end-uses. Selection of families with higher corewood stiffness has been a priority of the radiata pine breeding programme in New Zealand. Efforts are also being made to enhance gain through optimising the age of selection and the length of the generation interval.

Dungey et al. (2005) used SilviScan to estimate pithto-bark values for $\mathrm{MoE}$, and suggested that the optimum time to carry out these measurements was 7 years or less. The present study was conducted to address two main questions: (1) Do these results carry through to direct measurements of static bending MoE; can we confirm the SilviScan results on the optimum age for family selection to improve the stiffness of corewood? (2) Could selection based on corewood stiffness help improve outerwood stiffness, and vice versa?

\section{Material and Methods}

\section{Genetic Material and Sites}

Information from two progeny trials was used: (1) Kaingaroa Compartment 1350, and (2) Taylor's Block, both in the North Island of New Zealand. Both sites are high-index and fertile, but Taylor's Block is relatively more fertile because it was ex-pasture.

Kaingaroa Cpt 1350: A progeny test of open-pollinated (OP) progenies from about 600 radiata pine plus-trees was established in 1969 (SHELBOURNE and LOW, 1980). The trial was established as five replicates of 10-tree row-plots on a site in northern Kaingaroa Forest in the central North Island of New Zealand. The experiment was thinned at age 7 years, some localised thinning around selected plus trees was undertaken at age 12 years, and finally a commercial thinning at age 18 years. The age- 7 thinning reduced stocking to half of the original, leaving the best five trees standing in each plot. The age-18 thinning was a heavy commercial thinning that brought the stocking down to 280 stems per hectare. At ages 5 and 10 years, the parents were ranked based on progeny performance for various traits, including growth, form, disease resistance and pilodyne penetration (for wood density). The top 50 parents and their forwards-selected offspring were deployed in seed orchards.

In 1999, when the progenies were 30 years old, nine trees were sampled from each 50 top-ranked families, by one 5-mm breast-height $(1.4 \mathrm{~m})$ pith-to-bark increment core for X-ray densitometry analysis (KUMAR and LEE, 2002). The purpose was to understand the genetics of ring-density components and assess the possibilities of early selection for wood density. In addition to the $5-\mathrm{mm}$ core, one 12-mm breast-height pith-to-bark increment core was also taken from each of the same trees for SilviScan analysis (DuNGeY et al., 2005). Various traits, including wood density (DEN), microfibril angle (MfA) and predicted Modulus of Elasticity (MoE) were evaluated for each growth ring. SilviScan predicted MoE was a function of density and a diffractometric parameter (related both to the orientation of S2 microfibrils and to their proportion) (EvANs, 2003). Further details on the assessment technique, and the estimates of genetic parameters for DEN, MfA and predicted MoE, for each growth ring, have been reported (DUNGEY et al., 2005).

In this study, only SilviScan predicted MoE was considered for further analysis. Since many observations in the first and second growth rings, and in the last five rings towards the bark were missing, these rings were excluded from the analysis. Area-weighted average MoE was obtained for different ring groups (i.e. rings $3-5$, $6-10,1-10,11-15,16-20,21-25)$. These average ringgroup $\mathrm{MoE}$ values were treated as separate traits in further genetic analysis. The purpose of grouping rings was to evaluate the genetic gain achievable in different ring groups when selection is based on a particular group of rings.

Taylor's Block: This experiment consists of 18 paircrosses generated from mating among 23 parents from 50 parents selected in the Kaingaroa Cpt 1350 trial. The pair-cross offspring were planted in 1985 in large blocks of 49 trees each. There was only one block for each paircross and thus no replicates. At the age of 14 years, eight trees were felled randomly from each pair-cross for evaluating the pith-to-bark pattern of stiffness. Three clearwood sticks $(300 \times 20 \times 20 \mathrm{~mm})$ from each of two opposite radii (North and South) were cut from a diametrical slab at $1.4 \mathrm{~m}$ from the base i.e., six sticks were taken from each tree. Where possible, the sticks were taken to include the same growth rings in each tree, nominally centered on rings 3-4 (Position 1), rings 6-7 (Position 2), and rings 9-10 (Position 3) from the pith. These sticks were tested using the static-bending technique (MACK, 1979), and density (DEN), stiffness (MoE) and strength (Modulus of Rupture - MoR) were estimated for each sample. Further details of sampling procedures were reported earlier by JEFFERSON et al. (2001). 
Although the pair-crosses in the Taylor's Block were planted in unreplicated blocks, this is not expected to bias the estimates either of MoE itself or the genetic parameters, but merely increase their standard errors. Since pair-cross effects and block effects were confounded, it was assumed that microenvironmental effects within each block were similar. Confounding of family and block effects could result in overestimate of genetic parameters.

\section{Statistical analysis}

\section{Kaingaroa Cpt 1350}

As multi-tree row plots were used in the trial design, the full model for statistical analysis included replicate, family, replicate $x$ family, and residual factors. Preliminary analysis revealed that replicate and replicate $x$ family effects were non-significant. Thus, the following simple model was used for single-trait analysis:

$$
Y_{i j}=\mu+f_{i}+e_{i j}
$$

where $Y_{i j}$ is the phenotypic value for the $j^{\text {th }}$ individual in the $i^{t h}$ OP family for a given trait; $\mu$ is the general mean; $f_{i}$ is the random effect of $i^{\text {th }}$ family; $e_{i j}$ is the random within-family effect. Estimates of narrow-sense heritability $\left(\hat{h}^{2}\right)$ and family-mean heritability $\left(\hat{h}_{f}^{2}\right)$ for each trait were obtained from:

$$
\begin{aligned}
& \hat{h}^{2}=4 \hat{\sigma}_{f}^{2} /\left(\hat{\sigma}_{f}^{2}+\hat{\sigma}_{w}^{2}\right) \\
& \hat{h}_{f}^{2}=\hat{\sigma}_{f}^{2} /\left(\hat{\sigma}_{f}^{2}+\hat{\sigma}_{w}^{2} / n\right)
\end{aligned}
$$

where $\hat{\sigma}_{f}^{2}$ and $\hat{\sigma}_{w}^{2}$ are the estimated among-family and within-family variances, respectively; and $n$ is the average number of half-sib offspring per family. Significance of the among-family component of variance was interpreted as heritability being significantly greater than zero (LYNCH and WALSH, 1998, page 560).

\section{Taylor's Block trial}

An individual-tree model (see BoRrALHo, 1995) was used to analyse data from this experiment. Assuming a single fixed factor (the population mean: $\mu$ ) under the simplest individual-tree model, the phenotype $(Y)$ for each individual can be expressed as:

$$
Y_{j}=\mu+a_{j}+e_{j}
$$

where $a_{j}$ is the additive genetic value of $j^{\text {th }}$ individualtree and $e_{j}$ is the residual (which includes non-additive genetic and environmental effects) effect with variances $\sigma_{A}^{2}$ and $\sigma_{E}^{2}$ respectively. In this model, all additive effects are pooled (via numerator relationship matrix) into the individual-tree effect. Interrelationships, if any, among pair-crosses are also accounted for in the above individual-tree model. Estimates of $h^{2}$ were obtained from:

$$
\hat{h}^{2}=\hat{\sigma}_{A}^{2} /\left(\hat{\sigma}_{A}^{2}+\hat{\sigma}_{E}^{2}\right)
$$

Multivariate analyses were also conducted by treating $\mathrm{MoE}$ from rings $3-4,6-7$, and $9-10$ as separate traits. Estimates of genetic correlation $\left(r_{g}\right)$ were obtained from:

$$
\hat{r}_{g}=\hat{\sigma}_{x y} / \sqrt{\hat{\sigma}_{x}^{2} \times \hat{\sigma}_{y}^{2}}
$$

where $\hat{\sigma}_{x y}$ is estimated additive genetic covariance between two traits; $\hat{\sigma}_{x}^{2}$ and $\hat{\sigma}_{y}^{2}$ are estimated additive genetic variances for the two traits. Data for $\mathrm{MoE}$ were very similar for both radii (North and South) and showed similar estimates for heritability. Also, the correlations between $\mathrm{MOE}$ at opposite radii were generally high (discussed later). Thus, further analyses were conducted on the average (over the two radii) MoE for each of the three ring groups. ASREML (GILMOUR et al., 1997) and SAS PROC GLM (SAS InstituTE INC., 1989) software were used for implementing univariate and multivariate analyses in this study. Genetic gains from direct or indirect selection were estimated following FALCONER and MACKAY (1996, page 189 Equation 11.3, page 317 Equation 19.6). Non-linear models could also be used for estimating genetic parameters, but such models have generally been used only for discrete traits and are reported to yield higher heritability estimates compared to linear models (e.g. MATos et al. 1997).

\section{Results and Discussion}

\section{Kaingaroa Cpt 1350 trial}

Area-weighted average $\mathrm{MoE}$ was $3.5,8.0$ and 16.9 GPa in rings 3-5, 6-10 and 21-25 respectively (Table 1). The coefficients of variation $(\mathrm{CVs})$ declined from about $28 \%$ in rings $1-5$ to about $18 \%$ in rings $20-25$, indicating reduced variation among trees with increasing age (Table 1). It is interesting how, even in the outerwood, the $\mathrm{CV}$ for $\mathrm{MoE}$ is much higher than that for density $(\approx 10 \%)$, even though there is evidence (e.g. Cown et al., 1999) that MfA is not an important determinant of MoE in the outerwood. On the one hand, this might be interpreted in terms of a straight-line relationship of MoE on density having a substantial negative intercept (BURDON et al., 2001). On the other hand, the apparent volatility of $\mathrm{MoE}$ (but not density) following a production thinning would suggest that mild compression wood and tree-specific increases in MfA were coming into play.

In general, the narrow-sense heritability $\left(h^{2}\right)$ estimates for MoE were very high $(\geq 0.65)$ in the corewood (Table 1), but for the outer growth rings were less than half of those in the corewood. Interestingly, the family differences for MoE in rings 16-20 and 21-25 were not significant $(\mathrm{P} \geq 0.02)$. Family differences were not significant for individual-ring $\mathrm{MoE}$ (especially rings 15, 20 and 21 - DunGEY et al., 2005), which could explain the lower $h^{2}$ estimates in rings 21-25. It seems likely that additional environmental variation, caused by the thinnings that occurred shortly prior to the formation of rings 15, 20 and 21, would have made the expression of genetic variation less clear statistically, rather than causing an absolute reduction in the expression of genetic variation.

Estimates of phenotypic and genetic correlations between MoE of different ring groups are shown in Table 2. Most of these correlations were strong and positive, but were weaker with increasing separation of ring positions. This is consistent with results from individual 
ring data (DungeY et al., 2005). Phenotypic correlations of $\mathrm{MoE}$ in corewood rings $1-10$ with $\mathrm{MoE}$ in rings $11-15$, $16-20$ and $21-25$ were $0.63,0.37$ and 0.24 respectively (Table 2). The corresponding estimated genetic correlations were $0.91,0.65$ and -0.08 respectively (Table 2 ). The MoE in the ring group 21-25 was poorly correlated genetically with $\mathrm{MoE}$ in earlier ring groups. These estimated age-age genetic correlations between corewood and outerwood MoE are relatively lower compared with others reported for DEN in radiata pine (e.g. BANNISTER and Vine, 1981; Burdon and Young, 1991; Kumar and LEE, 2002).

Correlated genetic responses in the corewood (rings 1-10) MoE, from selections made for rings 11-15 and 16-20 MoE, would be about $74 \%$ and $40 \%$, respectively, of the gain that could be achieved by direct selection for corewood (rings 1-10) MoE (Figure 1). The main reason for these lower efficiencies of indirect selection is the lower heritabilities of the selection traits (MoE of rings 11-15 and 16-20) (see Table 1). While selection in older trees for outerwood MoE to improve corewood MoE will be less effective, the prospects for early selection for corewood $\mathrm{MoE}$ are quite encouraging (Figure 1). Family selection based on rings $3-5$ and $6-8$ would provide about $90 \%$ and nearly $100 \%$ respectively, of the gain that would be achieved from selection based on rings 1-10. It should be noted that early selection, while efficient on a per-generation basis, is even more efficient on a per-unit-time basis.

\section{Taylor's Block trial}

The overall mean static-bending MoE increased from $2.4 \mathrm{GPa}$ for rings $3-4$ to $7.2 \mathrm{GPa}$ in rings $9-10$, reflecting a rapid pith-to-bark increase within the corewood (Table 3). The CVs (\%) of average clearwood MoE (Table 3 ) were very similar to those reported earlier (BURDON et al., 2001; Kumar, 2004). It was interesting to note that CVs were similar to those obtained for SilviScan predicted MoE in the corewood at Kaingaroa Cpt 1350 (see Table 1). The higher average $\mathrm{MoE}$ at Kaingaroa $\mathrm{Cpt}$ 1350 compared with Taylor's Block could be because the former is a forest site and the latter is a farm site. The

Table 1. - Means, phenotypic coefficients of variation (CV), estimates of narrow-sense heritability $\left(h^{2}\right)$, and approximate standard errors (SE) of area-weighted SilviScan predicted stiffness $(\mathrm{MoE})$ for different ring groups. Significance of $h^{2}$ estimates is also shown $(* P<0.01)$. Data were from the 50 openpollinated families from Kaingaroa Cpt 1350 trial.

\begin{tabular}{cccc}
\hline Trait / Ring group & Mean $(\mathrm{GPa})$ & $\mathrm{CV}(\%)$ & $h^{2}(\mathrm{SE})$ \\
\hline MoE 3-5 & 3.51 & 28 & $0.70^{*}(0.20)$ \\
MoE 6-10 & 8.02 & 23 & $0.65^{*}(0.19)$ \\
MoE 1-10 & 6.92 & 22 & $0.69^{*}(0.20)$ \\
MoE 11-15 & 13.97 & 19 & $0.29 *(0.15)$ \\
MoE 16-20 & 17.36 & 16 & $0.16(0.13)$ \\
MoE 21-25 & 16.85 & 18 & $0.18(0.13)$ \\
\end{tabular}

MoE values at Kaingaroa Cpt 1350 were SilviScan-predicted, while MoE values at Taylor's Block were obtained by static-bending. SilviScan aims to predict dynamic MoE rather than static $\mathrm{MoE}$ which could explain the different average $\mathrm{MoE}$ values at these two sites. The phenotypic correlations between $\mathrm{MoE}$ from opposing radii were $0.67,0.64$ and 0.56 at Positions 1,2 , and 3 respectively, while the estimated genetic intercorrelations were near-perfect $(\approx 0.99)$. Thus, further analyses were conducted on the average (over the two radii) MoE at each of the three positions.

Narrow-sense heritability $\left(h^{2}\right)$ estimates were 0.50 , 0.57 and 0.34 at Position 1 (rings $3 \& 4$ ), 2 (rings 6\&7) and 3 (rings $9 \& 10$ ) respectively (Table 4). These results, and results from the SilviScan ring-group averages, showed a tendency of lower $h^{2}$ for outerwood MoE. A previously reported $h^{2}$ estimate (e.g. KUMAR, 2004) of clearwood $\mathrm{MoE}$ from rings $9 \& 10$ was 0.25 with standard error (SE) of 0.11 , which is consistent with this study. Individual-ring $h^{2}$ estimates of SilviScan MoE also showed lower heritability estimates in the outerwood than in the corewood (DunGEY et al., 2005). These consistent results suggest that the heritability of outerwood $\mathrm{MoE}$ is indeed lower than that of corewood MoE.

Estimates of phenotypic and genetic correlations between clearwood $\mathrm{MoE}$ at different ring positions (Table 4) were positive and significant, but were weaker with increasing age difference. These results are similar to those obtained from Kaingaroa Cpt 1350 data. (see Table 2). Estimated genetic correlations of MoE at Position 3 with Position 1 and Position 2 were 0.41 and 0.52 respectively (Table 4). The family-mean correlations between Position 1: Position 2, Position 1: Position 3, and Position 2: Position 3 were $0.86,0.40$ and 0.50 respectively, which are very similar to the estimated genetic correlations. The estimated genetic correlations between various ring groups were generally slightly higher for SilviScan predicted MoE compared with clearwood static bending MoE (see Table 3). The cause for this was not known, but one possible reason could be that Silviscan MoE was predicted using the same function of density and a diffractometric parameter (related both to the orientation of S2 microfibrils and to their proportion) in each ring. Since DEN and MfA affect stiffness differently in different rings (Cown et al., 1999), using a common prediction function across all rings could inflate the correlation between MoE of different rings. Results from the Taylor's Block trial suggested that correlation between DEN and MoE would be stronger in the outerwood compared to that near the pith (Table 5), which is in accordance with Cown et al. (1999).

Predicted genetic gains were estimated assuming that average MoE across all three positions (rings 3-4, rings 6-7 and rings 9-10) was our target trait. It was assumed that the average MoE across all three positions could be interpreted as corewood MoE. If the selections were based on $\mathrm{MoE}$ in rings 3-4, rings 6-7 and rings 9-10, the predicted genetic gain in corewood MoE was about $82 \%, 99 \%$ and $71 \%$, respectively, of the gain achievable from direct selection for corewood MoE. The 
Table 2. - Estimates of phenotypic correlations (above diagonal) and genetic correlations (below diagonal) between SilviScan predicted $\mathrm{MoE}$ in different ring groups. Approximate standard errors of genetic correlation estimates are shown in parentheses. *Significant $(P<0.01)$ phenotypic correlations. Data were from the 50 open-pollinated families from Kaingaroa Cpt 1350 trial.

\begin{tabular}{ccccccc}
\hline & MoE3-5 & MoE6-10 & MoE1-10 & MoE11-15 & MoE16-20 & MoE21-25 \\
\hline MoE 3-5 & - & $0.67^{*}$ & $0.78^{*}$ & $0.36^{*}$ & $0.18^{*}$ & 0.12 \\
MoE 6-10 & $0.90(0.07)$ & - & $0.97^{*}$ & $0.68^{*}$ & $0.39^{*}$ & $0.27^{*}$ \\
MoE 1-10 & $0.93(0.05)$ & 0.99 & - & $0.63^{*}$ & $0.37^{*}$ & $0.24^{*}$ \\
MoE 11-15 & $0.89(0.17)$ & 0.93 & $0.91(0.11)$ & - & $0.76^{*}$ & $0.54^{*}$ \\
& & $(0.01)$ & & & & \\
MoE 16-20 & $0.80(0.32)$ & 0.63 & $0.65(0.28)$ & $0.80(0.18)$ & - & $0.78^{*}$ \\
& & $(0.28)$ & & & & \\
MoE 21-25 & $0.26(0.33)$ & -0.18 & $-0.08(.36)$ & $-0.07(0.50)$ & $0.41(0.42)$ & - \\
& & $(0.38)$ & & & & \\
\hline
\end{tabular}

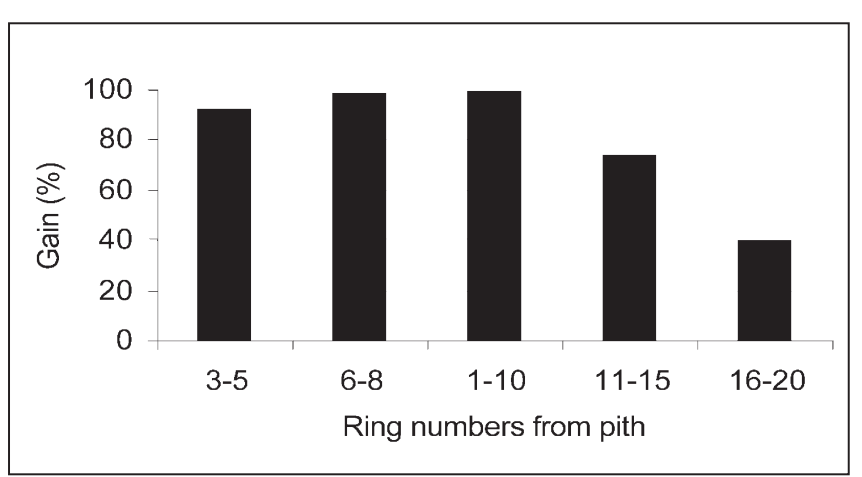

Figure 1. - Predicted indirect gain (expressed as percentage of direct selection) in corewood (rings 1-10) MoE when selection is made on the basis of $\mathrm{MoE}$ in different ring groups at Kaingaroa Cpt 1350.

predicted gains from Taylor's Block trial are quite similar to those obtained from the Kaingaroa Cpt 1350 trial, where selection for rings $3-5$ gave about $90 \%$ of the gain achievable from direct selection for corewood (rings 1-10) MoE.

\section{Strategies for improvement of stiffness}

The practicality, precision and cost of the assessment technique are critical in determining which technique to use to assess stiffness in progeny trials. For example, it is currently too costly to assess stiffness using SilviScan on $12 \mathrm{~mm}$ increment cores, and thus it is not a preferred technique for assessing large progeny trials. Similarly, assessing stiffness using clearwood sticks cut from standing trees is even more expensive and time-consuming. However, both of these techniques (SilviScan and clearwood sticks) provide an opportunity to understand the genetic control of the pith-to-bark patterns of stiffness. Another two options that are currently being evaluated, in the New Zealand radiata pine breeding programme, are acoustic tools for use on cut logs (e.g. HITMAN) and standing trees (e.g FAKOPP, IML Hammer, and ST300).

The narrow-sense heritability estimates of MoE from HITMAN measurements were reported to be about 0.25 in 14-15 year-old trials, compared with about 0.65 in a 10-year-old trial (KUMAR, 2004). Results to date suggests that the genetic control of stiffness could be categorised

Table 3. - Means and coefficients of variation (CV) of clearwood static-bending $\mathrm{MoE}$ at Taylor's Block (18 pair-cross families). Positions 1, 2 and 3 approximately represent rings $3-4,6-7$ and $9-10$ respectively.

\begin{tabular}{cccc}
\hline Radii & Position & Average (GPa) & CV $(\%)$ \\
\hline North & 1 (rings 3-4) & 2.4 & 21 \\
& 2 (rings 6-7) & 3.7 & 31 \\
& 3 (rings 9-10) & 7.2 & 23 \\
South & 1 (rings 3-4) & 2.4 & 20 \\
& 2 (rings 6-7) & 3.6 & 31 \\
& 3 (rings 9-10) & 7.2 & 25 \\
Average & 1 (rings 3-4) & 2.4 & 18 \\
& 2 (rings 6-7) & 3.7 & 28 \\
& 3 (rings 9-10) & 7.2 & 21 \\
\hline
\end{tabular}


Table 4. - Estimates of genetic (below diagonal) and phenotypic (above diagonal) correlations between breast-height clearwood static-bending $\mathrm{MoE}$ at three positions $(\mathrm{P} 1=$ rings $3-4, \mathrm{P} 2=$ rings $6-7, \mathrm{P} 3=$ rings $9-10)$ at Taylor's Block. Heritability $\left(h^{2}\right)$ estimates at each position are shown on the diagonal. Approximate standard errors are shown in parentheses. *Significant $(P<0.01)$ phenotypic correlations.

\begin{tabular}{cccc}
\hline & Rings 3-4 & Rings 6-7 & Rings 9-10 \\
\hline Rings 3-4 & $\mathbf{0 . 5 0}(0.20)$ & $0.67^{*}$ & $0.31^{*}$ \\
Rings 6-7 & $0.95(0.07)$ & $\mathbf{0 . 5 7}(0.21)$ & $0.50^{*}$ \\
Rings 9-10 & $0.41(0.34)$ & $0.52(0.29)$ & $\mathbf{0 . 3 4}(0.17)$
\end{tabular}

Table 5. - Estimates of correlations between density (DEN) and static-bending $\mathrm{MoE}$ of clearwood sticks at three positions (P1: rings 3-4, P2: rings 6-7, P3: rings 9-10) at Taylor's Block. Approximate standard errors of estimated genetic correlations are shown in parentheses. Probabilities of significance (* $p \leq 0.05$;** $p \leq 0.01$; ns Non-significant) of phenotypic and family-mean correlations are also shown.

\begin{tabular}{cccc}
\hline Type of correlation & Rings 3-4 & Rings 6-7 & Rings 9-10 \\
\hline Phenotypic & $0.21^{*}$ & $0.17^{*}$ & $0.69^{* *}$ \\
Genetic & $0.51(0.29)$ & $0.23(0.33)$ & $0.78(0.17)$ \\
Family-mean & $0.47^{*}$ & $0.27^{\mathrm{ns}}$ & $0.76^{* *}$ \\
\hline
\end{tabular}

as 'strong' in the corewood zone while 'moderate' in the outerwood zone. The age of assessment and the associated genetic parameters would determine the efficiency of selection for corewood MoE. Assuming corewood MoE was the target trait, the results presented in this study have shown that the efficiency of selection based on outerwood MoE would generally be lower than selection based on a few early growth rings of corewood. There are two explanations for these results. First, the heritability of outerwood $\mathrm{MoE}$ is generally lower than the $\mathrm{MoE}$ of early growth rings. Second, when selection is based on the early growth rings, the selection trait is a part of the target trait.

Since the estimated genetic correlation between $\mathrm{MoE}$ in rings 1-10 and MoE in rings 21-25 was very low (see Table 2), selection for MoE in corewood will not yield much gain in outerwood MoE (particularly rings 21-30). Cown et al. (1999) showed that both DEN and MfA had significant effect on corewood MoE, but DEN alone explains the majority of variation in the outerwood MoE. Selection for DEN, which is highly heritable, is an option for indirect improvement in stiffness (JAYAWICKRAMA, 2001; KUMAR et al., 2002). Results from Taylor's Block trial suggested a moderate-to-high correlation (see Table 5) between DEN and MoE of clearwood sticks. In addition, KUMAR (2004) showed that the estimated genetic correlation between stiffness (assessed using HITMAN on 5-m logs) and DEN (assessed using disc segments) varied between 0.44 and 0.64 in $10-15$ yearsold progeny trials. In the light of these results, it appears that indirect selection for corewood DEN could yield only moderate gain in the corewood MoE but significant gain in the outerwood $\mathrm{MoE}$.

Genetic correlations between corewood and outerwood DEN have been reported to be very high (e.g. BuRDON and YounG, 1991; Kumar and LeE, 2002), and density is also the major factor influencing $\mathrm{MoE}$ in the outerwood (Cown et al., 1999). These genetic correlations are higher than those between corewood MoE and outerwood $\mathrm{MoE}$ in the present data. Since the estimated genetic correlations between MOE and DEN are moderate in the corewood, the early selection based only on MOE could result in selecting some families with low DEN, which could badly affect the outerwood stiffness. It should be noted (see Table 1) that at Kaingaroa Cpt 1350 (a forest site), SilviScan predicted MoE of outerwood was more than $15 \mathrm{GPa}$, and thus the added cost of increasing it through selection might not be worthwhile. However, it is desirable to improve both corewood- and outerwood MoE for trees planted at farm sites (such as Taylor's Block) and various sites in the South Island of New Zealand (DAVE COWN, pers. comm.). Thus, inclusion of DEN and MoE, assessed at an early age, in a selection index would help improve both corewood and outerwood MoE. The weightings of the two terms could depend very much on the relative importance attached to improving MoE in the corewood and outerwood respectively. It has now become relatively cost-effective to measure DEN (using 5-mm increment cores) and acoustic MoE in standing trees, and thus could be used as selection criteria to improve stiffness of both corewood and outerwood.

Our results from both trials showed that assessment of stiffness in rings 6-7 would provide maximum genetic gain in corewood MoE. Early selection, using MoE of rings $3-5$, provided about $90 \%$ of the gain that would be achieved from selection based on $\mathrm{MoE}$ of rings 1-10. It should be noted, however, that cores (and sticks) were sampled at breast-height, and thus tree itself would actually be about two year older than a given core age. If there is to be additional emphasis on improving both outerwood MoE as well as corewood MoE, then family selection based on DEN and acoustic MoE, assessed at age 6-7 years, would be a good option. We have considered only the properties of clearwood in this paper, but other work (e.g. Cown et al., 1987; MATHESON et al., 1997) suggests that knot size is a major determinant for board degrade in sawmills. Including some estimate of potential knot size (such as branch size or branch cluster frequency) with acoustic measures of MoE and DEN at approximately age 7 would be beneficial. Using such a strategy would avoid costly destructive sampling and allowing preservation of all trees in tests for later assessments and forwards selection.

\section{Acknowledgements}

The data that was used in this project was obtained from work funded by the Radiata Pine Breeding Company, the Australian Forest and Wood Products Research and Development Corporation, CSIRO, New Zealand Foundation for Research, Science and Technology and ISAT (International Science and Technology Linkages Fund). The work would not have been possible without 
the willing help of the SilviScan team, in particular DAVID Menz, Sharee Harper, Kirsty Sui and Dr. Geoff DownEs. Thanks are due to all those involved in the Juvenile Wood Index project, particularly JoHN LEE, TOBY Stovold, Marco Lausberg, Paul Jefferson and Dave Cown. Rowland Burdon, Tony Shelbourne and Luis Gea are thanked for useful comments on an earlier version of this manuscript.

\section{References}

ANONYMUs (2001): Electronic Hammer: Instructions for Use and Guarantee Conditions. Instrumenta Mechanik Labor (IML) GmbH. Wiesloch, Germany.

BANNister, M. H. and M. H. VINE (1981): An early progeny trial in Pinus radiata. 4. Wood density. N. Z. J. For. Sci. 11: 221-243.

Bethge, K. and C. MATTHeck (1998): Instruments for detection and evaluation of decay and wood quality in standing trees. In: Proceedings of the eleventh international symposium on nondestructive testing of wood. Madison, WI. Edited by D. G. Pollock. Forest Products Society, Madison, USA. pp. 105-115.

BIER, H. and R. A. J. BRITTON (1999): Strength properties of small clear specimens of New Zealand-grown timbers. Forest Research Bulletin No. 41, NZ Forest Research Institute, Rotorua, New Zealand.

BuRDON, R. D. and G. Young (1991): Preliminary genetic parameter estimates for wood properties from topranked Pinus radiata progenies and comparison with controls. In: Proceedings of the Australian Forest Council Research Working Group No. 1 Meeting, Mt Gambier. Edited by C. HANEL and C. DEAN. Australian Forest Council RWG, Mt Gambier, Australia. pp. 137-140.

Burdon, R. D., R. A. J. BRITTON and G. B. WALFORD (2001): Wood stiffness and bending strength in relation to density in four native provenances of Pinus radiata. N. Z. J. For. Sci. 31: 130-146.

BorRalHo, N. M. G. (1995): The impact of individual tree mixed models (BLUP) in tree breeding strategies. In: Proceeding of the CRCTHF-IUFRO Conference: Eucalyptus plantations: Improving fibre yield and quality, Hobart, Australia. Edited by B. M. Poтts and N. M. G. BorRAlHO. Cooperative Research Centre for Temperate Hardwood Forestry, Sandy Bay, Tasmania, Australia. pp. 141-145.

Cown, D. J., M. O. Kimberley and I. D. Whiteside (1987): Conversions and timber grade recoveries from radiata pine logs. New Zealand Forest Research Institute, Bulletin No. 128. pp. 147-161.

Cown, D. J., J. HeBert and R. BALL (1999): Modelling Pinus radiata lumber characteristics. Part 1: Mechanical properties of small clears. N. Z. J. For. Sci. 29: 203-213.

Dungey, H. S., A. C. Matheson, D. Kain and R. Evans (In press): Genetics of wood stiffness and its components traits in Pinus radiata. Can. J. For. Res..

Evans, R. (2003): Wood stiffness by x-ray diffractometry. In: Proceedings of the workshop "Characterisation of the cellulosic cell wall", Grand Lake, Colorado, USA. Southern Research Station, University of Iowa and the Society of Wood Science and Technology.

FALCONER, D. S. and T. F. C. MACKAY (1996): Introduction to Quantitative Genetics. $4^{\text {th }}$ Edition. Addison Wesley Longman Ltd., Essex, UK.

Gilmour, A. R., R. THompson, B. R. Cullis and S. J. WelHAM (1997): ASREML User's manual, New South Wales Agriculture, Orange, Australia.
HARRIS, P. and M. ANDREws (1999): Tools and acoustic techniques for measuring wood stiffness. In: Proceeding of the $3^{\text {rd }}$ Wood Quality Symposium: Emerging Technologies for evaluating wood quality for wood processing, Rotorua, New Zealand. Edited by J. STULEN and B. APTHORP. Forest Industry Engineering Association, Rotorua, New Zealand. pp. 76-88.

JAYAWICKRAMA, K. J. S. (2001): Breeding radiata pine for wood stiffness: review and analysis. Aus. For. 64: $51-56$.

JefFerson, P. A., J. Lee, R. D. Ball and D. J. Cown (2001): Development of a juvenile wood index. New Zealand Radiata Pine Breeding Cooperative, Unpublished report.

KUMAR, S. (2004): Genetic parameter estimates for wood stiffness, strength, internal checking and resin bleeding for radiata pine. Can. J. For. Res. 34: 2601-2610.

KumAR, S. and J. LeE (2002): Age-age correlations and early selection for end-of-rotation wood density in radiata pine. For. Gen. 9: 323-330.

Kumar, S., K. J. S. JayaWiCKRAma, J. LeE and M. LausBERG (2002): Direct and indirect measures of stiffness and strength show high heritability in a wind-pollinated radiata pine progeny test in New Zealand. Silvae Genet. 51: 256-261.

Launay, J., M. Ivkovich, L. Paques, C. Bastien, P. HIGELIN and P. ROZENBERG (2002): Rapid measurement of trunk MOE on standing trees using RIGIDIMETER. Ann. For. Sci. 59: 465-469.

LindstrÖM, H., P. HARRIS and R. NAKADA (2002): Methods for measuring stiffness of young trees. Holz als Roh und Werkstoff 60: 165-174.

LYNCH, M. and B. WALSH (1998): Genetics and Analysis of Quantitative Traits. Sinauer Associates, Inc., Sunderland, MA, USA.

MACK, J. J. (1979): Australian method for mechanically testing small clear specimens of timber. Building Research Technical Paper (Second Series) No. 31, CSIRO, Australia.

Matheson, A. C., D. J. Spencer, J. G. Nyakuengama, J. YANG and R. Evans (1997): Breeding for wood properties in radiata pine. Pp. 169-179. In: BuRdon, R. D., MoORE, J. M. (Ed.) "IUFRO '97 Genetics of Radiata Pine". Proceedings of NZ FRI-IUFRO Conference 1-4 December and Workshop 5 December, Rotorua, New Zealand. FRI Bulletin No. 203.

Matheson, A. C., R. L. Dickson, D. J. Spencer, B. Joe and J. ILIC (2002): Acoustic segregation of Pinus radiata logs according to stiffness. Ann. For. Sci. 59: 471-477.

Matos, C. A. P., D. L. Thomas, D. Gianola, R. J. TempelMAN and L. D. Young (1997): Genetic analysis of discrete reproductive traits in Sheep using linear and nonlinear Models: I. Estimation of Genetic Parameters. J. Anim. Sci. 75: 76-87.

Ross, R. R. (1999): Using sound to evaluate standing timber. Int. For. Rev. 1: 43-44.

Ross, R. R. and R. F. PELleRIN (1991): Non-destructive testing for assessing wood members in structures: A review. USDA Forrest Service, Forest Products Laboratory GTR-70.

SAS InstituTE INC. (1989): SAS/STAT User's Guide, Version 6, Fourth Edition, Volume 2, SAS Institute Inc., Cary, NC, USA.

Shelbourne, C. J. A. and C. B. Low (1980): Multi-trait index selection and associated genetic gains of Pinus radiata progenies at five sites. N. Z. J. For. Sci. 10: 307-324. 
WALKER, J. F. C. and R. NAKADA (1999): Understanding corewood in some softwoods: a selective review on stiffness and acoustics. Int. For. Rev. 1: 251-259.

Xiping, W., R. J. Ross, J. R. ERICKSON, J. W. Forsman, M. McClellan, R. J. Barbour and R. F. Pellerin (2000): Nondestructive evaluation of standing trees with stress wave methods. In: Proceedings of the $12^{\text {th }}$ International Symposium on Nondestructive Testing of Wood, Hungary. Edited by F. Divos and R. F. PELLERIN. University of Western Hungary, Sopron. pp. 197-206.

\title{
Estimating Genetic Parameters for Wood Density of Scots Pine (Pinus sylvestris L.)
}

\author{
By A. FrIEs ${ }^{1)}$ and T. ERICSSON ${ }^{2)}$
}

(Received $28^{\text {th }}$ October 2005)

\begin{abstract}
Wood density was analysed and annual ring width was measured on increment cores from 1400 trees in a 30-year-old full-sib progeny test of Scots pine (Pinus sylvestris L.) in north Sweden. Genetic parameters for wood density were analysed separately for ten outer annual rings, and for simple averages of the five most recent years. The evaluation included genetic correlations with height and stem diameter. Heritabilities of density estimated separately for each annual ring was 0.14-0.26 without any age trend, and jointly for the ten or five latest rings $0.30-0.33$; for height growth it was 0.30-0.42 and for stem diameter 0.11-0.13. Additive genetic correlations with height and stem diameter were negative with the simplest statistical model $\left(\hat{r}_{A}=-0.425\right.$ and 0.511 , respectively) but vanished or diminished when ring width was added as covariate. Density breeding values calculated for the parent trees for each of ten annual rings separately varied considerably between parent trees and between years, tending to increase with increasing age, with a substantial increase between the ages 14 to 16 years from the pith. This age fits well with literature data on the change from juvenile to mature wood. The genetic correlation for wood density between rings from different years was high: $\hat{r}_{A}=0.8$ ten years apart, increasing to 1.0 for neighbouring rings. The high genetic correlations for wood density between the innermost and outermost annual rings indicate possible strong covariation between juvenile and/or transition wood and mature wood. The annual variation in wood density in relation to genetic regulation, phenology, environmental conditions, and development from juvenile to mature age is discussed.
\end{abstract}

Key words: annual ring density, annual ring width, breeding value, genetic correlation, heritability, juvenile wood, mature wood, multitrait REML, repeated-measurement model, wood density.

\footnotetext{
$\left.{ }^{1}\right)$ Corresponding author: ANDERS FRIES, Department of Forest Genetics and Plant Physiology, Swedish University of Agricultural Sciences, SE-90183 Umeå, Sweden. Ph: +4690 78683 68, Fax: +4690786 8165. E-mail: anders.fries@genfys.slu.se.

2) Tore ERICsson, Skogforsk, Box 3, SE-918 21 Sävar, Sweden. Ph: +469020333 50, Fax: +46902033360. E-mail: tore.ericsson@skogforsk.se.
}

\section{Introduction}

There is an increasing pressure on the forest resources in Sweden and elsewhere. This includes both higher demand on economic profitability and a stronger opinion for saving forest land for nature conservation, recreation etc. To meet these conflicting demands, biomass, cellulose and wood production per unit area must be increased from the forests that are cut. A high wood density implies furthermore a higher production of wood biomass per unit volume. The economic pressures are also tending to favour shorter rotations, making the quality of the juvenile wood increasingly important (cf. KOUBAA et al., 2000). The quality of wood, juvenile or mature, can be improved in various ways, but appropriate breeding can clearly play a major role.

Thus, high biomass and cellulose yields from harvested wood are important breeding goals, and high wood density is a crucial trait for attaining them (e.g. ERICSON et al., 1973). Scots pine (Pinus sylvestris L.) breeding in Sweden has to date focused on survival, vitality, branching traits and volume growth, but little on wood density. However, in many studies phenotypic and genetic correlations between wood density and height have been found to be negative, as reviewed for spruce (Picea ssp.) in ROZENBERG and CAHALAN (1997) and reported for western hemlock (Tsuga heterophylla (Raf.) Sarg.) in KING et al. (1998). In Scots pine trees, HaNnRUP et al. (2000) reported genetic and phenotypic correlations between wood density and height close to zero, while wood density and ring width were negatively correlated for four different year intervals between the ages 2 and 33 years. There is a risk, therefore, that any increase in volume obtained may be counteracted by reductions in density. The need to assess this risk, and to explore the scope for avoiding it, prompted the combined analysis of wood density, height growth and ring width presented here.

Numerous pine studies have described positive correlations between wood density and strength properties of the wood, e.g. wood density and modulus of rupture (MOR) (ERICSON et al., 1973; WANG and WANG, 1999) and modulus of elasticity (MOE) in both juvenile and mature 